\title{
Política de Acolhimento e Juventude: A Problemática da Inserção na Formação Profissional
}

\author{
Noemia Soares Barbosa Leal ${ }^{1}$ \\ ${ }^{1}$ Universidade Federal da Paraíba, PB, Brasil.
}

\author{
Maria de Fatima Pereira Alberto ${ }^{1}$ \\ ${ }^{1}$ Universidade Federal da Paraíba, PB, Brasil
}

\begin{abstract}
Resumo: $\mathrm{O}$ artigo objetiva analisar as relações que a política de acolhimento estabelece com a juventude em idade de inserção na formação profissional. Pressupõe-se que não há um planejamento sistematizado da política de acolhimento voltado à inserção dos jovens que atendam ao critério de idade na formação profissional, havendo ações pontuais e descontínuas. Trata-se de uma pesquisa qualitativa e exploratória de campo, realizada em sete instituições de acolhimento de um município da Paraíba. A pesquisa documental foi guiada por um protocolo elaborado pelas autoras, a partir do qual se buscaram informações para caracterização dos(as) jovens e das experiências registradas como a formação acessada. No diário de campo, fizeram-se anotações de caráter reflexivo, especulativo e descritivo. Procedeu-se a uma análise descritiva e de conteúdo, baseada na literatura que trata da temática. Os resultados apontam que dos(as) 51 jovens caracterizados(as), apenas 29 foram inseridos(as) na formação profissional, com prevalência no programa Jovem Aprendiz. Dentre os obstáculos mais enfatizados para inserção na formação profissional, está a defasagem escolar dos(as) jovens, que, somada à falta de clareza dos(as) profissionais sobre o que configura a formação profissional, conduziu a inserções em qualificações diversas e desvinculadas de uma proposta de inserção no mercado de trabalho. Aponta-se a necessidade de investimento na política de acolhimento em sua articulação com a política de formação profissional, a fim de contribuírem para o desenvolvimento juvenil, com potencial de colaborar para a construção de projetos de vida e para a inserção no mercado de trabalho.
\end{abstract}

Palavras-chave: Juventude, Acolhimento Institucional, Formação Profissional, Política Social.

\section{Foster Care Policy and Youth: The Problem of Insertion in Vocational Training}

\begin{abstract}
This paper analyzes the relations established between foster care policy and youth of vocational training age. We assumed a lack of systematic planning by the foster care policy aimed at young people of vocational training age, with only specific and discontinuous actions. This qualitative and exploratory field research was carried out in seven host institutions in a municipality of Paraíba. Guided by a protocol developed by the authors, the documentary research sought to characterize these young people and their experiences, such as the training accessed. The field diary consisted of reflective, speculative, and descriptive observations. After, the data collected underwent descriptive and content analysis, based on the literature regarding this topic. Results show that, of the 51 young individuals characterized, only 29 accessed vocational training, with prevalence of the Jovem Aprendiz program. Among the major obstacles for insertion in vocational training is the learning discrepancy of these young people, which, added to the professionals' lack of clarity on what constitutes vocational training, led to insertions in diverse programs, disconnected from a proposal for entry in the labor market. These findings point out the need for investment in foster care policy articulated with a vocational training policy, as to contribute to youth development, and that may collaborate to the construction of life projects and to the insertion in the labor market.
\end{abstract}

Keywords: Youth, Foster care policy, Vocational training, Social Policy. 


\title{
Política de Acogida y Juventud: La Problemática de la Inserción en la Formación Profesional
}

\begin{abstract}
Resumen: Este artículo pretende analizar las relaciones que la política de acogida establece con los jóvenes en edad de insertarse en la formación profesional. Se supone que no existe una planificación sistemática de la política de acogida orientada a la inserción profesional de jóvenes que cumplan con el criterio de edad, sino acciones puntuales y discontinuas. Esta es una investigación cualitativa y exploratoria de campo, realizada en siete instituciones del acogida de un municipio de Paraíba (Brasil). La investigación documental estuvo guiada por un protocolo elaborado por las autoras, a partir del cual se buscó información para caracterizar a los/las jóvenes y las vivencias registradas como la formación que accedieron. En el diario de campo, se tomaron notas de carácter reflexivo, especulativo y descriptivo. Se realizó un análisis descriptivo y de contenido, con base en la literatura que trata el tema. Los resultados muestran que, de los/las 51 jóvenes caracterizados/as, solo 29 fueron incluidos/as en la formación profesional, con predominio en el programa Jovem Aprendiz. Entre los obstáculos más destacados para insertarse en la formación profesional, se encuentra el retraso escolar de los/las jóvenes, al que se suma la falta de claridad de los/las profesionales sobre lo que constituye la formación profesional, lo que propició inserciones en cursos diferentes y desconectados de una propuesta de inserción en el mercado laboral. Se señala la necesidad de invertir en la política de acogida vinculada con la política de formación profesional, con el fin de contribuir con el desarrollo juvenil y colaborar para la construcción de proyectos de vida y para la inserción en el mercado laboral.
\end{abstract}

Palabras clave: Juventud, Acogida Institucional, Formación profesional, Políticas Sociales.

\section{Introdução}

O presente artigo busca analisar as relações que a política de acolhimento estabelece com a juventude em idade de inserção na formação profissional. Considerou-se a faixa etária de 15 a 29 anos como juventude, em conformidade com a Política Nacional da Juventude (PNJ) (Novaes, Cara, Silva, \& Papa, 2006) e com o Estatuto da Juventude (Lei n. 12.852, 2013). O contexto de desenvolvimento da juventude a que nos referimos - a política de acolhimento - exige a compreensão de que as políticas sociais surgem como resposta às expressões da questão social no capitalismo.

Como construções cujo caráter histórico-estrutural está em grande medida relacionado às determinações econômicas e políticas, as políticas sociais são marcadas por contínuos avanços e recuos, não alcançando ganhos plenos para a totalidade da população, pois configuram-se comumente de forma fragmentada e setorializada (Behring \& Boschetti, 2011). Nos limites dos interesses capitalistas, e no contraponto deles, Prates (2016) sinaliza a importância de potencializar processos sociais emancipadores, tendo em vista que as políticas sociais também são espaços de lutas, resistências e ganhos diante das necessidades sociais dos sujeitos históricos. Portanto, elas representam "possibilidades de avanços no âmbito dos direitos humanos, sociais e da cidadania" (Sposati, 2011, p. 105), podendo ser centrais na agenda das lutas sociais e no cotidiano da vida dos sujeitos.

No âmbito dos direitos infanto-juvenis, as políticas sociais existentes foram possíveis a partir de pactos e ordenamentos jurídicos que romperam com o paradigma que distinguia a infância privilegiada dos menores marginalizados. O Estatuto da Criança e do Adolescente (ECA) (Lei n. 8.069, 1990) é um marco na definição de que todas as crianças e adolescentes são sujeitos de direitos e têm prioridade absoluta, determinando a garantia de condições para o pleno desenvolvimento e para o acesso e o exercício de direitos tais como a educação e a profissionalização.

Dentre as possibilidades de medidas protetivas elencadas pelo ECA, tem-se o acolhimento institucional, que corresponde à política de proteção social especial de alta complexidade integrante do Sistema Único de Assistência Social (Suas). Esse sistema, por sua vez, 
é regido pelos princípios organizativos da integralidade da proteção social e da intersetorialidade na articulação da rede socioassistencial com as demais políticas e órgãos setoriais (Ministério do Desenvolvimento Social e Combate à Fome [MDS], 2012, art. $3^{\circ}$, III, IV) .

O princípio basilar da política de acolhimento institucional é a provisoriedade de sua aplicação, requerendo celeridade nos encaminhamentos e na efetivação da inclusão dos(as) acolhidos(as) na rede de serviços e equipamentos que compõe o Sistema de Garantia de Direitos (SGD). Para tanto, a estrutura e o funcionamento dessa política devem estar de acordo com os parâmetros estabelecidos nas Orientações técnicas para elaboração do Plano Individual de Atendimento (PIA) (MDS, 2018), na Tipificação nacional de serviços socioassistenciais (MDS, 2014), nas Orientações técnicas para os serviços de acolhimento para crianças e adolescentes (MDS, 2009) e na Resolução 113, do Conselho Nacional dos Direitos da Criança e do Adolescente (Conanda, 2006).

Contudo, as dificuldades de incorporar as frentes de trabalho prenunciadas nos documentos que normatizam o serviço refletem-se nas pesquisas empreendidas sobre a etapa da juventude vivida nesses espaços. Silva (2010), Honorato (2011), Moreira (2013), Romanelli (2013) e Leal (2016), dentre outros autores, discutem as dificuldades dos(as) jovens com trajetórias de vida em instituições de acolhimento para conseguir uma colocação no mercado formal de trabalho ante o estigma da institucionalização, a baixa escolaridade e a falta de formação profissional, bem como a precariedade com que esta se realiza.

No âmbito da política de acolhimento, há jovens que, à época da realização das pesquisas, não estudavam (Almeida, 2014), tinham mais de 14 anos e não haviam concluído o ensino fundamental (Leite, 2011) ou tinham os direitos educacionais negados já na infância (Silva, 2010). Esse segmento reflete um Estado que não cumpre seu papel de "assegurar, com absoluta prioridade, a efetivação dos direitos" (Lei n. 8.069, 1990, art. 4). Para Nascimento (2016), mesmo amparada em uma perspectiva protecionista, tal política pode legitimar práticas de atendimento que despotencializam as famílias e os indivíduos, concebendo-os a partir de atributos de inferioridade que justificam, por seu turno, a intervenção de especialistas para regular e tutelar suas vidas.

Assim como o acolhimento institucional, a formação profissional é uma forma de expressão da questão social, estando associada diretamente a uma luta de classes. Pessoa (2017) demarca que, historicamente, a formação profissional tem sido impulsionada pelo sistema corporativo, ofertando cursos, notadamente aos jovens pobres, que não proporcionam melhor inserção no mercado de trabalho ou ascensão social. Antes, apresentam-se como antídoto à criminalidade e à vagabundagem a que preconceituosamente se supõe que essa parcela da juventude estaria predisposta, ao desemprego e à falta de qualificação para o mercado de trabalho.

Para jovens enquadrados(as) nessas categorias, são criadas ações caracterizadas pela curta duração e por uma formação compensatória, restrita à inserção laboral, não impactando na diminuição da taxa de desemprego juvenil e tampouco abrangendo outras esferas da vida dos(as) jovens (Gonzales, 2009), como a formação educativa e humana. Apesar do uso difuso dos termos "qualificação profissional" e "formação profissional" os fazerem parecer sinônimos, há distinções: a qualificação é concebida como atividade de curta duração sem exigências quanto à titulação (Yannoulas \& Soares, 2009), enquanto a formação profissional, quando aliada à possibilidade de prosseguimento nos estudos e fundamentada na ciência, na cultura, na preparação para o trabalho e na tecnologia, pode oferecer condições adequadas para o desenvolvimento das potencialidades, proporcionando melhor qualidade de vida aos jovens (Bernardim, 2013).

Para os(as) jovens com trajetórias na política de acolhimento, constata-se uma pulverização na oferta dos cursos profissionalizantes, acessados por uma pequena parcela deles(as) (Felix, 2014), e uma incompatibilidade com seus interesses, demarcando possibilidade restrita de escolha (Leal, 2016). Essa problemática repercute na saída dos(as) jovens das instituições, que ocorre em muitos casos sem a segurança de que usufruirão da ampliação de oportunidades para a vida adulta (Almeida, 2014).

Para que sejam exequíveis as recomendações normativas que apregoam que o trabalho da política de acolhimento esteja voltado para a autonomia e a construção de projetos de vida dos(as) jovens, faz-se necessário superar o enfoque marginal, assistencialista e fragmentado com que operam os equipamentos e políticas setoriais, geralmente desvinculados das questões macroeconômicas e pouco articulados no enfrentamento das múltiplas determinações da questão social que afligem a juventude (Leite, 2011; 
Moreira, 2013; Silva, 2010). Abreu (2010) é contundente ao afirmar que o Estado deve ser competente no cumprimento de seu papel, garantindo o funcionamento de uma rede de atendimento capaz de satisfazer a demanda, sob o risco de afastar os sujeitos de seus núcleos de referência familiar e comunitário para aplicação de uma medida que deixa de ser protetiva e passa a ocasionar novas situações de violação de direitos, prejudicando o desenvolvimento.

Compreende-se que o desenvolvimento é guiado e perpassado por uma multiplicidade de variáveis que extrapolam os limites da herança biológica, dentre as quais estão as questões sociais, a trajetória de vida, as relações estabelecidas, o papel e o significado dos fatores ambientais. Por efeito, a materialidade e a qualidade das mediações refletem-se nas possibilidades de construção de projetos de vida pelos sujeitos históricos, pois é a partir dessa materialidade que os(as) jovens elegem projetos de vida palpáveis (Abrantes \& Bulhões, 2016; Pasqualini, 2016; Pessoa, 2017; Vigotski, 2017; Vygotski, 1996).

Em se tratando da juventude, as atividades que guiam os processos formativos do desenvolvimento gravitam em torno das atividades de estudo, assim como da escolha, da formação e do exercício profissional, o que requer a inserção dos(as) jovens “. . . em processos sociais mobilizadores de sua capacidade para elaboração de um projeto de vida e, igualmente, facilitadores de sua formação como sujeito ativo" (Abrantes \& Bulhões, 2016, p. 245). O projeto de vida corresponde a uma construção singular, contínua, orientada para o futuro e perpassada pelas possibilidades concretas da vida e do contexto (Mandelli, Soares, \& Lisboa, 2011).

A formação profissional, por sua vez, tem como proposta abarcar um desenvolvimento técnico-profissional metódico - em compatibilidade com o desenvolvimento físico, moral e psicológico do(a) aprendiz -, cujas operações alternadas entre teoria e prática tenham começo, meio e fim (Decreto n. 6.629, 2008; Decreto n. 9.579, 2018; Lei n. 10.097, 2000). Para tanto, o(a) aprendiz deve ser guiado(a) pela aprendizagem, visto que o trabalho educativo corresponde à “. . . atividade laboral em que as exigências pedagógicas relativas ao desenvolvimento pessoal e social do educando prevalecem sobre o aspecto produtivo" (Lei n. 8.069, 1990, art. 68).

Ressalvados os limites na operacionalização das propostas de formação profissional que ocorrem em sujeição aos interesses capitalistas, os pesquisadores têm identificado que a participação dos(as) jovens nos programas de formação auxilia a construção de projetos de vida, promovem espaços de socialização, conhecimento e identificação com profissões, serve como espaço ao papel de proteção social e auxilia na entrada no mercado de trabalho (Pessoa, 2017; Pessoa, Alberto, Máximo, \& Souza, 2014; Máximo, 2012). Diante disso, ressalta-se que a formação profissional não é suficiente, mas deve alcançar os(as) jovens com trajetórias em acolhimento, proporcionando-lhes elementos para autonomia e construção de projetos de vida. Ademais, como enfatizam Nunes e Fernandez (2016), as políticas sociais devem respeitar as especificidades do segmento jovem, de modo a atender suas necessidades e promover seus direitos.

Para tanto, em 2018 foi promulgado o Decreto n. 9.579, o qual dispôs, dentre outros temas, sobre o adolescente e o aprendiz e, em seu artigo 66, $\$ 5^{\circ}$, estabeleceu que os adolescentes e os(as) jovens em situação de acolhimento institucional constituem público prioritário para contrato de aprendizagem profissional. Mas o que, de fato, é ofertado em termos de formação profissional para os(as) jovens acolhidos(as) institucionalmente? E quem são os(as) jovens atendidos(as) pela política de acolhimento de um município do estado da Paraíba? Nosso pressuposto é que não há um planejamento sistematizado da política de acolhimento voltado à inserção dos(as) jovens acolhidos(as), que atendam o critério de idade na formação profissional, havendo ações pontuais e descontínuas.

\section{Método}

Tratou-se de uma pesquisa qualitativa e exploratória de campo, em que se "trabalha com o universo de significados" sobre determinado tema (Minayo, 2001, p. 22), realizada diretamente no local dos levantamentos. Identificaram-se na pesquisa, a partir dos documentos, jovens na condição de acolhidos(as) e egressos(as) do acolhimento, os(as) quais serão tratados neste artigo. Foram cumpridos todos os preceitos éticos pertinentes à Resolução n. 510 do Conselho Nacional de Saúde (2016), com a devida aprovação do Comitê de Ética (CAAE 87237218.6.0000.5188).

\section{Lócus}

A pesquisa foi realizada em instituições de acolhimento de um município da Paraíba. Das nove 
instituições de acolhimento existentes, sete participaram da pesquisa por preencherem os critérios de trabalhar ou ter trabalhado com jovens com idade para formação profissional, abrangendo jovens em situação de acolhimento entre 15 e 18 anos e egressos(as) entre 18 e 24 anos. Portanto, o recorte temporal da pesquisa contemplou os anos de 2007 a 2018.

\section{Instrumentos e técnicas}

Foi empregada a pesquisa documental, guiada por um protocolo elaborado pelas autoras e pelo diário de campo. A pesquisa documental se deu mediante o acesso a fontes primárias, constituídas por dados que não receberam tratamento científico (Helder, 2006; Sá-Silva, Almeida \& Guindani, 2009). Assumiu-se como documento qualquer suporte que contivesse informações e que pudesse servir para a consulta, incluindo impressos e manuscritos (Appolinário, 2009). O protocolo foi elaborado com o objetivo de direcionar a pesquisa documental, a partir da busca por informações que permitissem caracterizar os(as) jovens sexo, idade, motivo do acolhimento e status de institucionalização - e identificar as informações relativas à inserção destes(as) na formação profissional.

Os documentos acessados foram os prontuários individuais dos(as) jovens, elaborados e mantidos pelas equipes técnicas das instituições de acolhimento, somados a documentos remetidos por outras instâncias do SGD. Os critérios para pesquisa documental foram: integrar os prontuários de instituições de acolhimento que tivessem jovens acolhidos(as) ou egressos(as) com inserção na formação profissional durante o período de acolhimento; referir-se a jovens entre 15 e 29 anos, que estivessem acolhidos(as) no momento da coleta ou tivessem sido desligados(as) entre os anos de 2007 e 2018, a fim de enquadrar-se na faixa etária assumida como juventude.

O diário de campo foi apropriado como ferramenta descritivo-analítica para registro de informações que extrapolavam os documentos, por não terem sido neles identificadas ou por demandarem confirmação ou esclarecimento. Tais anotações derivaram de conversas informais com os(as) coordenadores(as) ou integrantes da equipe técnica (psicólogo(a) e/ou assistente social); da observação em campo; das contradições e conflitos identificados, assim como das impressões e reflexões oriundas da pesquisa (Triviños, 1987; Lima, Mioto, \& Prá, 2007), cujos registros ampliaram o universo informacional do trabalho.

\section{Procedimento de análise dos dados}

Parte dos dados resultantes da pesquisa documental, obtidos mediante uso do protocolo, foram analisados descritivamente (média), a fim de caracterizar os(as) jovens com trajetória em acolhimento e a formação profissional por eles(as) acessada. A análise de conteúdo (Minayo, 2010) guiou a categorização de outra parte dos dados - por exemplo, procedência dos documentos e tipo de formação acessada. Do diário de campo foram retirados trechos para aprofundar a análise e a reflexão dos dados coletados.

\section{Resultados e Discussões}

\section{Pesquisa documental: ponto de partida da investigação}

A política de acolhimento tem como preceito normativo a organização de um banco de dados com registro de informações sobre o PIA de cada sujeito institucionalizado. O registro documental é uma atividade essencial para orientar o trabalho do serviço de acolhimento, pois, como estabelecido nas orientações técnicas (MDS, 2009), viabiliza a construção dinâmica de intervenções pautadas nas particularidades e necessidades específicas de cada caso, auxiliando o delineamento das táticas para o seu atendimento.

Dado esse caráter basilar para o serviço de acolhimento, acessar os prontuários dos(as) jovens foi um caminho fundamental para alcançar o objetivo desta pesquisa. Contudo, nessa investigação, a pesquisa documental se realizou com limites previstos por Appolinário (2009) quanto à incompletude e à imprecisão, além do que se observou sobre a não atualidade dos registros. Algumas das instituições dispunham de prontuários com apenas a identificação do nome dos(as) jovens, ou algum outro documento esparso, o que dificultou a coleta dos dados requeridos pelas pesquisadoras. Essa problemática não é específica de apenas uma das instituições pesquisadas, como identificamos:

A consulta ao/a coordenador(a) e/ou membro da equipe técnica tem sido adotada como estratégia complementar diante da ausência de registros os mais básicos nos prontuários dos(as) jovens, havendo casos de jovens que estão há meses no acolhimento, mas sem as informações básicas registradas. É também preocupante que prontu- 
ários sejam perdidos na mudança de imóvel ou de gestão, como apontaram alguns profissionais (Diário de Campo, agosto de 2018).

Os motivos assinalados pelos(as) profissionais diante da inexistência ou imprecisão dos documentos incluíram a perda destes na mudança de imóvel; a má estrutura das casas, que resultou em acidentes (como inundações ou desabamento de teto), danificando os recursos materiais; e a mudança do quadro de funcionários, que incidiu no extravio e desaparecimento de documentos. Dentre o que foi acessado, identificou-se uma variabilidade de documentos que podem estar contidos nos prontuários dos(as) jovens, o que aponta para a complexidade da política de acolhimento em sua articulação em rede (MDS, 2009, 2012), no atendimento as demandas específicas de cada sujeito.

A diversidade dos documentos incluiu relatórios elaborados por políticas e serviços públicos, sendo categorizados de acordo com os eixos estratégicos do SGD (Lei n. 8.069, 1990; Conanda, 2006). Correspondendo ao eixo de defesa, foram encontrados documentos procedentes de órgãos públicos judiciais (juizado da infância e juventude), público-ministeriais e do Conselho Tutelar, aos quais incumbe a garantia do acesso à justiça, mediante mecanismos jurídicos de proteção legal dos direitos. No eixo de promoção, os documentos identificados derivaram de políticas de atendimento em favor da garantia dos direitos, tais como o Centro de Referência de Assistência Social (Cras), o Centro de Referência Especializado de Assistência Social (Creas), a escola e o próprio serviço de acolhimento, além de documentos relativos a certificados de cursos ofertados por Organizações Não Governamentais (ONG) e instituições educacionais de nível superior públicas ou privadas.

Não foram identificados documentos elaborados ou remetidos por organizações representativas do eixo de controle, o qual é exercido pela sociedade civil, como os conselhos dos direitos e os de controle de políticas públicas. E, não enquadrados nos eixos estratégicos do SGD, foram acessados documentos pessoais de identificação (como RG), registros da história de vida escritos (diário, carta) e iconográficos (fotografia, desenho) e, principalmente, documentos de acompanhamento dos(as) jovens durante o período em que estavam em acolhimento, os quais descrevem aspectos da história de vida pessoal e familiar, bem como o comportamento do(a) jovem e os encaminhamentos realizados.
Os documentos referentes à formação profissional encontrados restringiram-se à cópia do contrato com o programa de aprendizagem e ao registro informativo da inserção na formação profissional ou em algum curso, os quais constavam no PIA ou em quadros com o resumo da demanda do caso elaborados para audiências de acompanhamento.

Diante dos limites encontrados quanto ao acesso de prontuários desatualizados ou imprecisos, entende-se que a lacuna no registro de informações sobre os(as) jovens remete ao não ajustamento da política de acolhimento às diretrizes normativas para a elaboração do PIA. A negligência às recomendações sobre a imediaticidadade na elaboração do PIA e o conteúdo das informações a constarem nesse documento (Lei n. 8.069, 1990, arts. 94, XX, 101, §4- $\$ 6^{\circ}$; MDS, 2009, pp. 26-30, 2018) dificulta a investigação sobre as características dos(as) jovens com trajetórias nessa política e sobre o trabalho desenvolvido em prol da juventude institucionalizada, notadamente acerca dos compromissos firmados para sua inserção em atividades educativas e de formação para o trabalho.

Como ressaltam Lima et al. (2007), "a documentação não pode ser negligenciada no contexto do exercício profissional" (p. 94), na medida em que tem relevância no planejamento e na sistematização da realidade, além de demonstrar a qualificação das ações profissionais e, acrescenta-se, da estruturação da política social. Considerados os limites no desenvolvimento da pesquisa documental, as informações acessadas não representam a totalidade de jovens com trajetórias institucionais dentro dos critérios elencados para este estudo. Há, portanto, que se considerar que as políticas são cenário de "conflitos de interesses e é resultado de decisões que visam administrar esses conflitos" (Nunes \& Fernandez, 2016, p. 66).

Problematiza-se, portanto, o lugar que esses(as) jovens ocupam na política de acolhimento e os aspectos considerados essenciais em suas trajetórias de vida para nortear a ação do serviço. O predomínio de registros quanto a aspectos familiares e comportamentais dos(as) jovens parece apontar para a regulação e tentativa de controle e gestão da vida, como discute Nascimento (2016). As situações de negligência elencadas como justificativa para o acolhimento são desconectadas da responsabilidade do próprio Estado como garantidor e defensor de direitos, recaindo sobre as famílias e os indivíduos. 
Considerada como problema social, a juventude exige um desdobrar de políticas sociais que atendam as contingências dos(as) jovens para um desenvolvimento saudável e condizente com suas potencialidades, direcionando-os(as) a processos educativos e de profissionalização. Entretanto, a realidade documental dos serviços de acolhimento é um indício de como tal política é operacionalizada, o que torna ineficaz constituí-la como um suporte amplo o suficiente para atender as necessidades dos sujeitos ou para proporcionar a autonomia.

\section{Quem são os jovens atendidos pela política de acolhimento em um município do estado da Paraíba?}

No município da Paraíba em que a pesquisa documental foi realizada, identificou-se que, entre os anos de 2007 e 2018, havia 51 jovens com trajetórias na política de acolhimento institucional dentro do critério de idade correspondente à categoria juventude, variando entre 15 e 24 anos, com média de 18 anos e moda de 17 anos. Quanto ao status de institucionalização, 26 estavam acolhidos(as) à época da coleta e 25 desligados das instituições, na condição de egressos(as). Destes(as), 21 eram do sexo feminino e 30 do sexo masculino, dos(as) quais 29 preenchiam o segundo critério, a saber, terem sido inseridos(as) na política de formação profissional durante o período de acolhimento, como pode ser observado na Tabela 1:

\section{Tabela 1}

Caracterização do(as) jovens identificados(as) na pesquisa documental.

\begin{tabular}{lll}
\hline \multicolumn{2}{c}{ Variáveis } & $\mathrm{n}$ \\
\hline \multirow{2}{*}{ Sexo } & Feminino & 21 \\
& Masculino & 30 \\
Status de & Acolhido(a) & 26 \\
institucionalização & Egresso(a) & 25 \\
Inserção na Política de & Sim & 29 \\
Formação Profissional & Não & 22 \\
\hline
\end{tabular}

Os motivos registrados para o acolhimento desses(as) jovens são os mais variados, remetendo a expressões da questão social, tais como abandono, transferência de comarca, violência (psicológica, física e/ou sexual), situação de rua, processo de adoção malsucedido, pobreza, dependência química dos cuidadores e gravidez decorrente de abuso sexual, dentre outros. Tais motivos estão engendrados em uma complexa teia de violações de direitos, o que requer que as trajetórias dos(as) jovens em acolhimento sejam dignificadas. Além disso, como aponta Honorato (2011), o bem-chegar, o bem-estar e o bem-sair devem refletir um exercício cotidiano de valorização dos aspectos subjetivos e coletivos que apontem para a possibilidade de construção de novos projetos de vida.

Assim como a juventude, o projeto de vida também é uma construção processual intimamente relacionada com a realidade objetiva e social, e com suas implicações (Mandelli et al., 2011). É no movimento de vir a ser, que entrar em contato com os elementos mediadores do desenvolvimento pode potencializar saltos qualitativos, já que, como ressalta Pasqualini (2016), a forma e a estrutura das funções psíquicas humanas percorrem caminhos distintos por dependerem das circunstâncias histórico-culturais.

Desse modo, as políticas sociais, como resposta do Estado ante as refrações da questão social (Behring \& Boschetti, 2011), também demarcam as condições objetivas de vida dos usuários. Elas precisam se expandir em quantidade e qualidade, atentando para as necessidades concretas de vida e incorporando demandas de direitos humanos e sociais (Sposati, 2011), tendo o sujeito como centro desse processo.

Do conjunto dos(as) jovens identificados(as) $(n=51)$, aqueles que estavam acolhidos(as) durante a realização da pesquisa $(n=26)$ tinham média de idade de 16 anos e, como se pode apreender a partir da Tabela 2, apenas quatro estavam, de fato, inseridos(as) na política de formação profissional.

\section{Tabela 2}

Caracterização dos(as) jovens em acolhimento.

\begin{tabular}{llc}
\hline \multicolumn{2}{c}{ Variáveis } & $\mathrm{n}$ \\
\hline Sexo & Feminino & 14 \\
& Masculino & 12 \\
Idade & 15 anos & 9 \\
& 16 anos & 8 \\
Status de & 17 anos & 9 \\
institucionalização & Acolhido(a) & 26 \\
Inserção na Política de & Sim & 4 \\
Formação Profissional & Não & 22 \\
\hline
\end{tabular}


Sobre a baixa representatividade dos(as) jovens acolhidos(as) que acessam a formação, os(as) coordenadores(as) indicaram o baixo nível de escolaridade como um dos motivos, somado, dentre outros, à pouca oferta de vagas para cursos de aprendizagem profissional.

$\mathrm{O}$ (a) coordenador(a) enfatiza que o "grande dilema” [sic] com o perfil dos(as) jovens acolhidos(as) é a distorção entre a idade e a série cursada, que a instituição não consegue sanar. Enfatiza ainda que há que se considerar que a maioria dos(as) jovens chegam na instituição com uma trajetória de direitos negados e com dificuldade de aderir as atividades propostas. Pontua que uma possibilidade de os(as) jovens terem maior margem de chance de participar das "poucas oportunidades" [sic] de formação profissional que surgem é com a aprovação em um exame escolar que permite reclassificá-los(as) quanto a série ou nível de ensino cursado (Diário de Campo, julho de 2018).

As dificuldades relacionadas ao nível de escolaridade ou de acesso e permanência na escola não são um achado inédito deste estudo, pois têm sido constatadas por outros pesquisadores, como Almeida (2014), Leite (2011), Abreu (2010) e Silva (2010). Estes, ao empreenderem pesquisas no acolhimento, identificam uma série de violações no âmbito do direito à educação, figurando como símbolo da omissão do Estado perante aqueles(as) que estão institucionalizados(as). No contraponto dessa realidade, a política de acolhimento tem como parâmetro técnico de funcionamento a orientação para viabilizar o acesso a programas de aceleração da aprendizagem para os casos de distorção série-idade, assim como a profissionalização (MDS, 2009).

O que se observou ao longo da pesquisa é que a própria noção de oportunidade desloca a discussão sobre as desigualdades que perpassam as trajetórias de vida dos(as) jovens antes e durante a aplicação da medida de acolhimento. $\mathrm{O}$ foco da oportunidade ignora o direito positivado em lei, e individualiza no(a) jovem, à responsabilidade por redefinir parte de sua trajetória, notadamente no que se refere à escolaridade - como nos casos dos exames de reclassificação escolar - e de inserção na formação profissional, via contratos de aprendizagem.
No que tange aos(às) egressos(as), foram identificados(as) 25 jovens nessa condição, em sua maioria do sexo masculino e com média de idade de 20 anos, os(as) quais foram inseridos(as) na formação profissional ainda durante o período em que estavam acolhidos(as), como pode ser observado na Tabela 3 . Diferentemente da caracterização dos(as) jovens acolhidos(as), a qual considerou jovens com ou sem inserção na formação profissional, a caracterização dos jovens egressos tratou de um grupo homogêneo quanto ao critério de inserção na formação profissional durante o período de acolhimento institucional.

Tabela 3

Caracterização dos(as) jovens egressos(as)

\begin{tabular}{|c|c|c|}
\hline \multicolumn{2}{|c|}{ Variáveis } & \multirow{2}{*}{$\frac{\mathrm{n}}{7}$} \\
\hline Crur & Feminino & \\
\hline SCAU & Masculino & 18 \\
\hline \multirow{7}{*}{ Idade } & 17 anos & 2 \\
\hline & 18 anos & 4 \\
\hline & 19 anos & 5 \\
\hline & 20 anos & 6 \\
\hline & 22 anos & 4 \\
\hline & 23 anos & 2 \\
\hline & 24 anos & 2 \\
\hline $\begin{array}{l}\text { Status de } \\
\text { institucionalização }\end{array}$ & Egresso/a & 25 \\
\hline $\begin{array}{l}\text { Inserção na Política de } \\
\text { Formação Profissional }\end{array}$ & Sim & 25 \\
\hline
\end{tabular}

Não foram identificados(as) egressos(as) com idade acima de 24 anos e registro de inserção na formação profissional, o que indica que o desligamento dos(as) jovens foi a partir de 2012. Nesse sentido, é pertinente pontuar que as normativas específicas dos programas de aprendizagem, as quais datam de 2000 (Lei n. 10.097, 2000) e 2018 (Decreto n. 9.579, 2018), dispõem sobre o direito à profissionalização e regulamentam dispositivos da Consolidação das Leis do Trabalho (CLT) para adolescentes e jovens aprendizes. Essa lacuna exige estudos aprofundados que busquem identificar as causas da não inserção de jovens em situação de acolhimento na política de formação profissional, via programas de aprendizagem, tendo em consideração o contexto político-econômico e as especificidades da política de acolhimento.

Para os(as) jovens que acessaram a política de formação profissional durante o período em que 
estavam acolhidos(as), essa experiência pode representar uma possibilidade de inserção no mercado de trabalho, dado o caráter de formação teórica e técnica. Contudo, tal equação pode não ser tão direta, por não ser uma garantia de emprego formal ante ao ritmo de contratação do mercado, além das lacunas no próprio processo de formação (Pessoa et al., 2014).

A peculiaridade do contexto de desenvolvimento dos(as) jovens em acolhimento e as experiências vividas nesse espaço criam diferentes situações de aprendizado (Romanelli, 2013). Também são importantes as experiências possibilitadas na interseção com outras políticas sociais. No caso das políticas de educação para o trabalho, Yannoulas e Soares (2009) explicitam que a dificuldade de formação de trabalhadores como sujeitos coletivos e históricos assenta-se no esvaziamento do trabalho como princípio educativo, característica própria do sistema capitalista. São os limites provenientes do modelo capitalista que, para Prates (2016), incidem em processos de inclusão precários.

Nesse sentido, é pertinente ressaltar que quando o ECA reconhece que crianças e adolescentes têm status de sujeitos de direitos a quem devem ser asseguradas as condições para o pleno desenvolvimento (Lei n. 8.069, 1990), aponta-se para a necessidade de identificar as atividades que potencialmente podem contribuir para tal desenvolvimento. Conforme o Estatuto da Juventude (Lei n. 12.852, 2013, art. $3^{\circ}$, III), há que se "ampliar as alternativas de inserção social do jovem, promovendo programas que priorizem o seu desenvolvimento integral", considerando também que inserção no mercado de trabalho é demanda de significativa parcela dessa população (Novaes et al., 2006).

Compreende-se assim, que a formação profissional é uma ferramenta que pode mediar o surgimento de formações qualitativamente novas e o curso do desenvolvimento, cujas vivências abrem espaço para as etapas seguintes da vida. E, como demarca Bernardim (2013), para a juventude da classe trabalhadora, o trabalho e a educação são espaços complementares de realização da condição juvenil, na medida em que contribuem para sua realização enquanto sujeitos históricos, por respeitar direitos outrora violados e possibilitar a inserção socioeconômica do(a) jovem. Diante disso, compreender as relações que a política de acolhimento estabelece com a juventude em idade de inserção na formação profissional requer identificar o que tem sido ofertado em termos de formação para esses(as) jovens.

\section{Qual é a formação ofertada aos(as) jovens acolhidos(as) institucionalmente?}

Majoritariamente, as informações identificadas acerca da formação direcionada aos(as) jovens durante a medida de acolhimento eram sobre encaminhamentos para cursos categorizados como "qualificação diversa", os quais foram registrados nos documentos elaborados pela equipe técnica das instituições de acolhimento e, sobretudo no PIA, que contém um campo específico a ser preenchido nesse sentido. Houve dificuldade na identificação do acesso à formação profissional que aliasse aprendizagem teórica e prática em conformidade com a Lei n. 10.097 (2000), a qual trouxe alterações à CLT, inseriu regras protetoras aos menores de 18 anos e ficou conhecida como Lei da Aprendizagem.

Quando solicitadas aos(as) profissionais do acolhimento informações que pudessem esclarecer os registros documentais ou a ausência destes, esses(as) profissionais não demonstraram clareza sobre o que constitui a formação profissional. Antes, referiam-se "a qualquer tipo de oportunidade de trabalho ou cursos profissionalizantes, independentemente da credibilidade da instituição proponente, do conteúdo, dos objetivos e da duração do curso, bem como da articulação entre teoria e prática" (Diário de Campo, junho de 2018).

De tal modo, os registros referentes aos cursos de qualificação diversa apontaram que 27 jovens acessaram oficinas e 29 jovens acessaram cursos técnicos de curta duração. Por oficinas compreendem a proposta de atividade temática não relacionada ao ensino de uma profissão específica. Já os cursos técnicos de curta duração agrupam qualificações relacionadas a uma atividade profissional, sem, contudo, aliar uma proposta formativa com teoria, prática e complexificação gradual das atividades de aprendizado, tal como se caracteriza a formação profissional (Lei n. 10.097, 2000). A participação dos jovens em uma dessas modalidades de qualificação diversa não é mutuamente exclusiva, de modo que há jovens - acolhidos(as) ou egressos(as) que acessaram as oficinas e/ou os cursos técnicos de curta duração e também que não acessaram nenhum desses cursos de qualificação.

Na Tabela 4 foi possível categorizar a qualificação diversa, caracterizando as oficinas e os cursos técnicos de curta duração quanto às formações a que fazem referência, as quais se aproximam do conceito de qualificação preceituado por Yannoulos e Soares (2009). 


\section{Tabela 4}

Caracterização da qualificação diversa acessada por jovens institucionalizados(as).

\begin{tabular}{|c|c|}
\hline Variáveis & \\
\hline Oficinas & $\begin{array}{l}\text { Arte (dança, pintura, origami) } \\
\text { Orientação profissional } \\
\text { Cidadania } \\
\text { Protagonismo } \\
\text { Pedagógica (reforço escolar, língua } \\
\text { estrangeira) } \\
\text { Ética }\end{array}$ \\
\hline $\begin{array}{l}\text { Cursos } \\
\text { Técnicos } \\
\text { de curta } \\
\text { duração }\end{array}$ & $\begin{array}{l}\text { Operador de caixa } \\
\text { Informática } \\
\text { Robótica } \\
\text { Salão de beleza (manicure, corte) } \\
\text { Corte e costura } \\
\text { Culinária } \\
\text { Higienização, manipulação de } \\
\text { alimentos e recursos pesqueiros }\end{array}$ \\
\hline
\end{tabular}

Tais qualificações foram nominalmente registradas em documentos como relatórios e PIA, contudo sem detalhes sobre carga horária, metodologia, objetivo, ementa ou frequência de encontros. Em algumas dessas qualificações, havia no prontuário dos(as) jovens seus certificados, o que permitia identificar a instituição proponente, a carga horária total, o período de realização e, em alguns casos, a ementa do curso. Como exemplo, tem-se a oficina de orientação profissional ministrada por uma ONG e o curso técnico de informática ofertado por instituições de ensino de nível superior. Já as oficinas pedagógicas e de artes, bem como os cursos técnicos de salão de beleza e corte e costura foram realizados por voluntários(as) nas próprias instituições.

Esses dados estão em consonância com outros estudos, que identificaram que, na margem dos $21,4 \%$ de acolhidos(as) inseridos(as) em cursos profissionalizantes, $36 \%$ acessaram os cursos na própria instituição de acolhimento (Felix, 2014); a qualificação oferecida não teve como meta a inserção no mercado de trabalho ou o direcionamento ao exercício de atividades compatíveis com a qualificação recebida (Moreira, 2013); isso amplia as dificuldades dos(as) jovens para se inserir ou competir no mercado de trabalho em cargos ou funções que exigem maior qualificação ou escolaridade, sendo obstáculo para a ascensão intelectual, cultural, social e econômica (Leal, 2016).

Apreende-se a partir das formações propostas aos(as) jovens acolhidos(as) que muitas das qualificações ofertadas, ainda que situadas como formação profissional, atendem mais a uma proposta de socialização ou de atividades informativas, tais como as que integram a categoria oficinas. Fica evidenciado que a política de acolhimento ainda é operacionalizada de modo precarizado, individualizando expressões da questão social, tais como a defasagem escolar e, ao não atuar no enfrentamento da problemática, em parceria com a rede socioassistencial, acaba por cumprir apenas um papel paliativo, por meio do qual o Estado assegura assistência mínima, sem confrontar os interesses capitalistas (Behring \& Boschetti, 2011).

Com isso, a política de acolhimento não consegue romper com conceitos e práticas prevalentes nos modelos institucionais dos séculos XIX e XX, pautados em iniciativas para o preenchimento do tempo tido como ocioso e improdutivo dos(as) jovens com atividades não necessariamente alinhadas aos seus interesses (Leal, 2016) e que não dialogam com as demandas reais de preparação e inserção no mercado de trabalho. Ao contrário, fortalece-se a manutenção de parcerias que não rompem os muros institucionais que por tanto tempo caracterizaram os modelos de instituições totais, por serem realizadas dentro do próprio serviço e com presença marcante de voluntários.

Em contrapartida, o trabalho para a construção e o fortalecimento de trajetórias autônomas exige necessariamente a imersão dos(as) jovens em atividades que se deem fora dos limites das instituições, em diálogo direito com a comunidade e outros atores sociais. Caso contrário, reatualiza-se o cenário identificado por Moreira (2013), em que, sobretudo para os(as) jovens de classe baixa e com trajetórias institucionais, a inserção no mercado de trabalho é marcada pela informalidade e precariedade dos vínculos trabalhistas, retroalimentando as barreiras para aumento da escolaridade e da qualificação decorrentes da fragilidade das políticas.

Tendo em vista essa discussão, para além da inserção em cursos de qualificação diversa, identificou-se que, dentre os(as) jovens com trajetórias no acolhimento e na formação profissional, a maior prevalência do programa de formação acessado foi no Jovem Aprendiz, com 25 jovens inseridos(as) (Tabela 5). Quanto a essa formação, Máximo (2012) e Pessoa (2017) avaliam a experiência de profissionalização como relevante nas trajetórias e projetos de vida de jovens, ainda que haja dificuldades para as empresas cumprirem as cotas estabelecidas em lei para aprendizes e conciliar estudos e trabalho seja um desafio para os(as) jovens que acessam o programa. 
Tabela 5

Formação Profissional Acessada.

\begin{tabular}{lc}
\hline \multicolumn{1}{c}{ Variáveis } & $\mathrm{n}$ \\
\hline Jovem Aprendiz & 25 \\
Programa Nacional de Acesso ao & 3 \\
Ensino Técnico e Emprego (Pronatec) & \\
Ensino Médio Integrado & 1 \\
Total & 29 \\
\hline
\end{tabular}

O requisito "ensino fundamental incompleto" abrangido pelo programa Jovem Aprendiz pode ser uma explicação para o maior alcance do público do acolhimento. De outro lado, o mesmo motivo relativo ao nível de escolaridade exigido pelo programa de formação pode ser uma explicação para a baixa incidência de jovens que acessam o Ensino Médio Integrado $(\mathrm{n}=1)$ e o Programa Nacional de Acesso ao Ensino Técnico e Emprego (Pronatec) $(n=3)$, o que indica que esses programas, por não terem pré-requisito quanto à idade, poderiam ser mais inclusivos para os(as) jovens de acolhimento. Contudo, por serem destinados a estudantes do ensino médio, excluem os(as) jovens com defasagem série-idade, conforme registrado em diário de campo, a partir do apontamento de um(a) dos(as) profissionais.

Com a mesma quantidade de jovens $(n=3)$ está a formação do Programa Nacional de Inclusão de Jovens (Projovem), tecido com o objetivo de garantir a convivência familiar e comunitária e criar condições para a inserção e permanência do(a) jovem no sistema educacional (Decreto n. 6.629, 2008). Este pode ser pensado como uma proposta ajustada ao objetivo basilar do acolhimento - reintegrar o(a) jovem a sua família -, o que aponta para a necessidade de estudos aprofundados sobre o baixo alcance dos(as) jovens com trajetórias em acolhimento, como identifica esta pesquisa.

Entende-se que a proposição de aliar a formação escolar e profissional está em consonância com as atividades-guia para o desenvolvimento dos(as) jovens. Contudo, nem todo ambiente ou aprendizagem contribui para o desenvolvimento integral tão enfatizado no ECA (Lei n. 8.069, 1990, art. $3^{\circ}$ ), sendo imprescindível atentar para a qualidade dos mediadores ofertados e para a materialidade das condições disponibilizadas, pois esses elementos guiam o curso do desenvolvimento e a projeção da vida. O trabalho educativo e formativo para o trabalho não pode estar restrito à mera certificação e incorporação de normas técnicas, mas deve tornar-se "um instrumento para a compreensão da realidade, em suas múltiplas determinações" (Leal \& Mascagna, 2016, p. 232).

Por outrolado, ainda que não seja razoável esperar que os programas de formação profissional confrontem a estrutura de classe preexistente na sociedade brasileira, é necessário envidar esforços para incorporar os(as) jovens ao mundo do trabalho, valorizando seu potencial e ampliando quantitativa e qualitativamente a força de trabalho brasileira (Gonzales, 2009). Para tanto, Nunes e Fernandes (2016) destacam a importância de que as políticas específicas para a juventude considerem a trajetória de vida não linear e as especificidades das trajetórias juvenis, marcadas por diferentes determinantes socioculturais.

Também a complementariedade e as especificidades dos serviços são fatores decisivos no alcance do atendimento das demandas juvenis em sua integralidade, pois o ambiente é a fonte de desenvolvimento para as características humanas mais desenvolvidas, como já apontava Vigotski (2017). Atingidos pelas refrações da questão social com intensidade, os sujeitos dos segmentos vulnerabilizados demandam do Estado a formatação de políticas sociais com padrões de proteção social e de enfrentamento das desigualdades (Behring \& Boschetti, 2011) no acesso e no usufruto dos direitos de educação e formação profissional de qualidade, como é o caso dos(as) jovens com trajetórias em acolhimento. Para estes(as), o desafio é pensar a construção de projetos de vida que abarquem as melhores possibilidades de desenvolvimento integral, ante a agudez com que experimentam as expressões da questão social.

Diante da complexidade e dos extensos desafios postos à política de acolhimento, assevera-se que o período em acolhimento só poderá ser exitoso, no sentido de ampliar o repertório cultural dos(as) jovens, se atender à condição fundamental de atuar em articulação com a rede socioassistencial, com os demais órgãos do SGD e com as políticas de saúde, educação, profissionalização, habitação, cultura, lazer e esporte, dentre outras. Como consta na Tipificação nacional de serviços socioassistenciais (MDS, 2014), a política do acolhimento assenta-se no objetivo específico de desenvolver "condições para a independência e o autocuidado" (p. 46), o que requer intencionalidade, planejamento e compromisso com a juventude. 


\section{Considerações finais}

As perspectivas de estudos no âmbito da política de acolhimento institucional parecem inesgotáveis, dada a riqueza de elementos que perpassam as trajetórias dos sujeitos que ali vivem parte de suas vidas, interseccionadas pelas políticas sociais. Tal cenário também constitui tema de interesse da psicologia debruçada em compreender como se dá o desenvolvimento juvenil em contextos diversos.

No esforço de analisar as relações que a política de acolhimento estabelece com a juventude em idade de inserção na formação profissional, empreendemos uma pesquisa documental em sete instituições de acolhimento de um município da Paraíba que atendem ou atenderam jovens com idade para formação profissional. Foram acessados os prontuários individuais de jovens acolhidos(as) e egressos(as), para identificar quem são e o que lhes é ofertado em termos de formação.

Nesse sentido, observou-se que a variedade quanto ao tipo e a procedência documental aponta para a necessidade de articulação da política de acolhimento com outros serviços e equipamentos da rede socioassistencial, como estratégia para responder à complexidade das trajetórias juvenis. Contudo, a não sistematização no registro, na atualização, na organização e no arquivamento dos prontuários individuais é um indicador do modo de operacionalização da política de acolhimento, refletindo na dificuldade para acessar e conhecer as características do público que atende, assim como os encaminhamentos realizados. Fica evidente a débil intervenção do Estado ante a responsabilidade de garantia da proteção social e do desenvolvimento para aqueles(as) que, segundo o ECA, são prioridade absoluta.

Identificou-se, dentre outras informações, que pequena parcela dos(as) jovens atualmente acolhidos(as) com idade para formação profissional de fato acessa programas de aprendizagem, os quais continuam operando de forma paliativa e com ganhos individuais em detrimento da coletividade. Isso confirma o pressuposto de que não há um planejamento sistematizado da política de acolhimento voltado à inserção dos(as) jovens que atendam ao critério de idade na formação profissional, havendo ações pontuais e descontínuas.

Falta também clareza do que configura a formação profissional para os(as) profissionais do acolhimento, o que, somado à defasagem escolar dos(a) jovens, concorre para a inserção em uma qualificação diversa, seja nos cursos técnicos, seja nas oficinas, ambas desvinculadas de uma proposta formativa que alie teoria e prática e seja voltada para a inserção no mercado de trabalho.

Como consequência de um ensino empobrecido, a formação ou qualificação restringe-se a instrumentalizar os(as) jovens nas competências mais elementares, que, no entanto, não contribuem para o desenvolvimento integral nem, tampouco, representam possibilidade de inserção no mercado de trabalho. A formação ou qualificação que, num primeiro momento, tem aparência de ganho para o(a) jovem institucionalizado(a), pode mostrar-se mais à frente insuficiente, ineficaz e excludente. Nesse sentido, os dados encontrados demonstram a necessidade de aprofundar os estudos a fim de compreender os objetivos que se pretende alcançar por meio da oferta e inserção dos(as) jovens nessa qualificação, visto que as ações da política de acolhimento devem estar previstas e intencionalmente definidas no projeto político-pedagógico.

Por outro lado, o projeto de vida não se restringe à formação para inserção no mercado de trabalho, mas deve estar relacionado a uma consciência coletiva e à apropriação da atividade de trabalho para as realizações mais desenvolvidas da humanidade. Destaca-se, portanto, a necessidade de mudanças nos rumos das políticas de educação e trabalho para que atendam às necessidades específicas dos(as) jovens e estejam em consonância com "as exigências pedagógicas relativas ao desenvolvimento pessoal e social do educando" (Lei n. 8.069, 1990, art. 68). Não há como avançar na inserção em formação profissional sem um trabalho para correção de fluxo escolar e, em se tratando da formação profissional, os(as) jovens devem ser guiados(as), sobretudo pela aprendizagem educativa, em que pese às metas produtivas enredadas nesse processo.

Feita essa ressalva, ainda que a articulação das políticas de acolhimento e de formação profissional tenha atuação limitada e seja incapaz de solucionar questões históricas que afligem a juventude, é posto o desafio de estruturá-las para atender as especificidades dessa população, considerando formas de resolutividade para a deficiência na formação e as desvantagens quanto ao capital educacional, cultural e social dos(as) jovens de setores marginalizados.

Diante dessas considerações, e tomando o acolhimento institucional como contexto de 
desenvolvimento para os(as) jovens caracterizados nesta pesquisa, sugere-se a discussão dos dados da pesquisa em grupos de trabalho em torno dos direitos juvenis, dos conselhos municipais dos direitos da criança e do adolescente e das secretarias vinculadas às políticas de acolhimento e formação profissional, bem como de educação.

Nessa oportunidade, deve-se evidenciar a urgência da ampliação de debates e avanços por parte do Estado, para que este atue como mediador no processo de desenvolvimento dos(as) jovens, atendendo suas contingências mediante a criação de programas de políticas sociais específicas na interseção do acolhimento com a formação profissional. Ressalta-se ainda que os elementos - e a qualidade destes - acessados pelos(as) jovens influem diretamente na constituição de subjetividades, na construção de projetos de vida e nas diferentes possibilidades de inserção no mercado de trabalho, repercutindo na sociedade como um todo.

\section{Referências}

Abrantes, A. A., \& Bulhões, L. (2016). Idade adulta e o desenvolvimento psíquico na sociedade de classes: Juventude e trabalho. In L. M. Martins, A. A. Abrantes, \& M. G. D. Facci (Orgs.), Periodização histórico-cultural do desenvolvimento psíquico: Do nascimento à velhice (pp. 241-266). Autores Associados.

Abreu, S. E. D. (2010). A criança em acolhimento institucional e o direito humano à educação infantil: sob as teias do abandono [Tese de doutorado, Universidade Federal da Paraíba]. Repositório Institucional da UFPB. https:// repositorio.ufpb.br/jspui/handle/tede/4603

Almeida, B. L. F. (2014). As instituições de acolhimento de João Pessoa: Avanços e perspectivas pós-Plano Nacional de Promoção, Proteção e Defesa do Direito de Crianças e Adolescentes à Convivência Familiar e Comunitária [Relatório de pesquisa não publicado]. Universidade Federal da Paraíba.

Appolinário, F. (2009). Dicionário de metodologia científica: Um guia para a produção do conhecimento científico. Atlas.

Behring, E. R., \& Boschetti, I. (2011). Política social: Fundamentos e história. Cortez.

Bernardim, M. L. (2013). Juventude, escola e trabalho: Sentidos atribuídos ao ensino médio por jovens da classe trabalhadora [Tese de doutorado, Universidade Federal do Paraná]. Acervo digital da UFPR. https://acervodigital.ufpr.br/handle/1884/34679

Conselho Nacional de Saúde. (24 maio 2016). Resolução n. 510, de 7 abril de 2016. Diário Oficial da União. https://bit.ly/3zNwhiX

Conselho Nacional dos Direitos da Criança e do Adolescente. (20 abr. 2006). Resolução 113, de 19 de abril de 2006. Diário Oficial da União, (76), 3-5.

Decreto n. 9.579, de 22 de novembro de 2018. (23 nov. 2018). Consolida atos normativos editados pelo Poder Executivo federal que dispõem sobre a temática do lactente, da criança e do adolescente e do aprendiz, e sobre o Conselho Nacional dos Direitos da Criança e do Adolescente, o Fundo Nacional para a Criança e o Adolescente e os programas federais da criança e do adolescente, e dá outras providências. Diário Oficial da União. https://bit.ly/3l2MMnd

Decreto n. 6.629, de 4 de novembro de 2008. (5 nov. 2008). Regulamenta o Programa Nacional de Inclusão de Jovens - Projovem. Diário Oficial da União. https://bit.ly/3l3HfwG

Felix, K. V. C. (2014). As instituições de acolhimento de João Pessoa/PB segundo a visão das crianças e dos adolescentes acolhidos: Avanços e desafios [Dissertação de mestrado, Universidade Federal da Paraíba]. Repositório Institucional da UFPB. https://bit.ly/3i9dCsf

Gonzales, R. (2009). Políticas de emprego para jovens: entrar no mercado de trabalho é a saída? In J. A. Castro, L. M. C. Aquino \& C. C. Andrade (Orgs.), Juventude e políticas sociais no Brasil (pp. 25-39). Ipea.

Helder, R. R. (2006). Como fazer pesquisa documental. Universidade do Algarve.

Honorato, A. A. S. (2011). O significado do momento da saída de adolescentes de instituição de acolhimento ao completarem a maioridade civil: E agora? [Dissertação de mestrado, Pontifícia Universidade Católica de São Paulo]. Biblioteca Digital PUC-SP. https://tede2.pucsp.br/handle/handle/17533

Leal, N. S. B. (2016). Sujeitos de direitos ou sujeitos de tutela? Memórias de jovens egressos sobre o acolhimento institucional em João Pessoa (2010-2015) [Dissertação de mestrado, Universidade Federal da Paraíba]. Repositório Institucional da UFPB. https://bit.ly/2UQ19Rq 
Leal, Z. F. R. G., \& Mascagna, G. C. (2016). A adolescência inicial: comunicação íntima pessoal, atividade de estudo e formação de conceitos. In L. M. Martins, A. A. Abrantes, \& M. G. D. Facci (Orgs.), Periodização histórico-cultural do desenvolvimento psíquico: do nascimento à velhice (pp. 221-237). Autores Associados.

Lei n. 12.852, de 5 de agosto de 2013. (6 ago. 2013). Institui o Estatuto da Juventude e dispõe sobre os direitos dos jovens, os princípios e diretrizes das políticas públicas de juventude e o Sistema Nacional de Juventude SINAJUVE. Diário Oficial da União. https://bit.ly/3i6njrk

Lei n. 8.069, de 13 de julho de 1990. (16 jul. 1990). Dispõe sobre o Estatuto da Criança e do Adolescente e dá outras providências. Diário Oficial da União. http://www.planalto.gov.br/ccivil_03/leis/L8069.htm

Lei n. 10.097, de 10 de dezembro de 2000. (20 dez. 2000). Altera dispositivos da Consolidação das Leis do Trabalho - CLT, provada pelo Decreto-Lei no 5.452, de 1o de maio de 1943. Diário Oficial da União. http://www.planalto.gov.br/ccivil_03/LEIS/L10097.htm

Leite, J. A. C. (2011). Família e proteção social nas instituições de acolhimento de crianças e adolescentes em João Pessoa-PB [Dissertação de mestrado, Universidade Federal da Paraíba]. Repositório Institucional da UFPB. http://tede.biblioteca.ufpb.br:8080/handle/tede/7219

Lima, T. C. S., Mioto, R. C. T., \& Prá, K. R. D. (2007). A documentação no cotidiano da intervenção dos assistentes sociais: algumas considerações acerca do diário de campo. Textos \& Contextos, 6(1), 93-104. https://bit.ly/2Vjhwp7

Mandelli, M. T., Soares, D. H. P., \& Lisboa, M. D. (2011). Juventude e projeto de vida: novas perspectivas em orientação profissional [Número especial]. Arquivos Brasileiros de Psicologia, 63, 1-104. http://pepsic.bvsalud.org/ $\mathrm{pdf} / \mathrm{arbp} / \mathrm{v63nspe/06.pdf}$

Máximo, T. A. C. O. (2012). Significado da formação e inserção profissional para gestores e aprendizes egressos do Programa Jovem Aprendiz [Tese de doutorado, Universidade Federal da Paraíba]. Repositório Institucional da UFPB. Recuperado de: https://bit.ly/2WwHjej

Minayo, M. C. de S. (2001). Pesquisa social: Teoria, método e criatividade (18a ed.).Vozes.

Minayo, M. C. de S. (2010). O desafio do conhecimento: pesquisa qualitativa em saúde (12a ed.). Hucitec.

Ministério do Desenvolvimento Social. (2018). Orientações técnicas para elaboração do Plano Individual de Atendimento (PIA) de crianças e adolescentes em serviços de acolhimento. https: / /bit.ly/3l4CHpX

Ministério do Desenvolvimento Social e Combate à Fome. (2009). Orientações técnicas para os serviços de acolhimento para crianças e adolescentes. https://bit.ly/3iVeCiz

Ministério do Desenvolvimento Social e Combate à Fome. (2012). Norma Operacional Básica: NOB - SUAS. https://bit.ly/2TFpOax

Ministério do Desenvolvimento Social e Combate à Fome. (2014). Tipificação nacional de serviços socioassistenciais. https://bit.ly/3ya7ndf

Moreira, I. M. (2013). Acolhimento institucional e qualificação profissional: Implicações da medida preventiva na vida do jovem egresso [Dissertação de mestrado, Universidade Estadual do Ceará]. Repositório Uece. https://bit.ly/3i552dP

Nascimento, M. L. (2016). Proteção e negligência: Pacificando a vida de crianças e adolescentes. Nova Aliança.

Novaes, R. C. R, Cara, D. T., Silva, D. M. da, \& Papa, F. de C. (Orgs.). (2006). Política Nacional da Juventude: diretrizes e perspectivas. Conselho Nacional da Juventude; Fundação Frederich Erbet. https:/ / bit.ly/3f6JKun

Nunes, M. B. A., \& Fernandez, C. B. (2016). Estado, sociedade e políticas de trabalho e emprego voltadas para os jovens no Brasil. Katálysis, 19(1), 64-72. http://dx.doi.org/10.1590/1414-49802016.00100007

Pasqualini, J. C. (2016). A teoria histórico-cultural da periodização do desenvolvimento psíquico como expressão do método materialista dialético. In L. M. Martins, A. A. Abrantes, \& M. G. D. Facci (Orgs.), Periodização histórico-cultural do desenvolvimento psíquico: Do nascimento à velhice (pp. 63-90). Autores Associados.

Pessoa, M. C. B. (2017). Política de formação profissional e contextos sociais: Trajetórias e projetos de vida de jovens [Tese de doutorado, Universidade Federal da Paraíba]. Repositório Institucional da UFPB. https://repositorio.ufpb.br/jspui/handle/tede/9132

Pessoa, M. C. B., Alberto, M. F. P., Máximo, T. A. C. O., \& Souza, P. C. Z. (2014). Formação profissional de jovens: A que se destina? Estudos de Psicologia, 19(1), 22-30. http://dx.doi.org/10.1590/S1413-294X2014000100004 
Prates, J. C. (2016). O método e a teoria marxiana. In I. F. Oliveira, I. L. Paiva, A. L. F. Costa, F. C. Lima, \& K. Amorim (Orgs.), Marx hoje: Pesquisa e transformação social (pp. 71-100). Outras Expressões.

Romanelli, B. M. B. (2013). O que é feito dos jovens? Dimensões psicossociais e educativas no processo de acolhimento institucional [Tese de doutorado, Universidade Federal do Paraná]. Acervo Digital da UFPR. https://acervodigital.ufpr.br/handle/1884/30049

Sá-Silva, J. R., Almeida, C. D., \& Guindani, J. F. (2009). Pesquisa documental: Pistas teóricas e metodológicas. Revista Brasileira de História \& Ciências Sociais, 1(1), 1-15. https://periodicos.furg.br/rbhcs/article/view/10351/0

Silva, M. E. S. (2010). Acolhimento institucional: A maioridade e o desligamento [Dissertação de mestrado, Universidade Federal do Rio Grande do Norte]. Repositório UFRN. https://bit.ly/3xaUYED

Sposati, A. (2011). Tendências latino-americanas da política social pública no século 21. Katálysis, 14(1), 104-115. https:// doi.org/10.1590/S1414-49802011000100012

Triviños, A. N. S. (1987). Introdução à pesquisa em ciências sociais: A pesquisa qualitativa em educação. São Paulo, Brasil: Atlas.

Vigotski, L. S. (2017). O problema do ambiente na pedagogia. In. A. M. Longarezi \& R. V. Puentes (Orgs.), Ensino desenvolvimental: Antologia: Livro I (pp. 15-38). Edufu.

Vygotski, L. S. (1996). La crisis de los siete años. In L. S. Vygotski, Obras escogidas IV: Psicología infantil (pp. 377-286). Visor.

Yannoulas, S., \& Soares, K. (2009). Políticas transversais (gênero, raça/etnia e deficiência) e educação/qualificação para o trabalho. Educação Unisinos, 13(1), 31-42. https://bit.ly/3rERZ64

\section{Noemia Soares Barbosa Leal}

Doutora em Psicologia Social pelo Programa de Pós-Graduação em Psicologia Social (PPGPS) da Universidade Federal da Paraíba (UFPB), João Pessoa - PB. Brasil.

E-mail: noemiasbleal@gmail.com

(1) https://orcid.org/0000-0001-8389-7834

\section{Maria de Fatima Pereira Alberto}

Professora titular do Departamento de Psicologia e do Programa de Pós-Graduação em Psicologia Social (PPGPS) da Universidade Federal da Paraíba (UFPB), João Pessoa - PB. Brasil.

E-mail: jfalberto89@gmail.com

(1) https://orcid.org/0000-0003-2515-9571

O presente trabalho foi realizado com apoio da Coordenação de Aperfeiçoamento de Pessoal de Nível Superior (Capes) por meio de bolsa de doutorado (código 001) concedida à primeira autora.

Endereço para envio de correspondência:

Universidade Federal da Paraíba (UFPB) - Centro de Ciências Humanas, Letras e Artes (CCHLA). Ambiente dos Professores, andar 1, sala 25, Cidade Universitária. CEP 58051-900. João Pessoa - PB. Brasil.

Recebido:01/03/2019

Aceito: $21 / 10 / 2020$

Received 03/21/2019

Approved 10/21/2020

Recibido 01/03//2019

Aceptado 21/10/2019 
Psicologia: Ciência e Profissão 2021 v. 41, e220685, 1-16.

Como citar: Leal, N. S. B., \& Alberto, M. F. P. (2021). Política de acolhimento e juventude: A problemática da inserção na formação profissional. Psicologia: Ciência e Profissão, 41, 1-16. https://doi.org/10.1590/1982-3703003220685

How to cite: Leal, N. S. B., \& Alberto, M. F. P. (2021). Foster care policy and youth: The problem of insertion in vocational training. Psicologia: Ciência e Profissão, 41, 1-16. https://doi.org/10.1590/1982-3703003220685

Cómo citar: Leal, N. S. B., \& Alberto, M. F. P. (2021). Política de acogida y juventud: La problemática de la inserción en la formación profesional. Psicologia: Ciência e Profissão, 41, 1-16. https://doi.org/10.1590/1982-3703003220685 